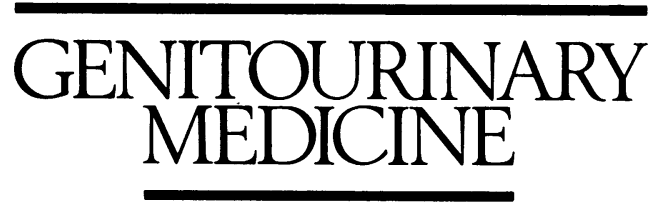

Editorial

\title{
Improvements in design and substance
}

Genitourinary Medicine has a new cover and a new design. We have maintained our familiar green colour and the contents are still to be found on the front cover. The larger pages (A4 size), altered layout and enhanced quality of illustrations give greater flexibility in the presentation of material and we believe lead to a more spacious, attractive and readable journal. We have also given the Journal a subtitle "The Journal of Sexual Health, STDs and HIV" which gives our readers, some of whom may be unfamiliar with the contents of Genitourinary Medicine, a clearer picture of our contents and coverage.

Over the last 12 months we have introduced two other changes to the Journal. Firstly, we have given our correspondence columns more space and prominence and we hope this will continue to encourage readers to submit letters to the editors. We accept letters for publication which deal with social or political issues, and small studies or case reports which do not contain sufficient scientific information to warrant publication as full papers. Our second change has been the introduction of structured abstracts. Several people have expressed reservations about this, mainly on the grounds of removing individual style and a decrease in readability. However, we believe that there are a number of advantages of structured abstracts including the provision of more informative and accurate information and a greater accessibility for people using electronic retrieval systems.

In 1992 we will continue to publish our series on laboratory techniques in genitourinary medicine and our popular AIDS clinico-pathological conferences. In addition, we will be publishing a new series of articles on the sensitive subject of sexually transmitted diseases in children, edited by Dr Greta Forster and Dr Steve Esterich and the introductory article appears in this edition.

The changes we have introduced are directed at improving the quality and readability of Genitourinary Medicine and we hope that they will meet with the approval of both readers and authors.

Academic Department Genitourinary Medicine

A MINDEL University College and Middlesex School of Medicine London W1N $8 A A$ 